\title{
IS CONSUMER CONFIDENCE INDEX A SUITABLE PREDICTOR OF FUTURE ECONOMIC GROWTH? AN EVIDENCE FROM THE USA
}

\author{
Jiří Mazurek, Elena Mielcová
}

\section{Introduction}

In general, an economic growth is defined as an increase in the capacity of an economy to produce goods and services, compared from one period of time to another. In macroeconomics, the economic growth is expressed by changes in real GDP. The existence of business cycles was observed and studied since $19^{\text {th }}$ century.

Later, the interest of macroeconomists focused on the prediction of business cycles, with an interest in forecasting upcoming recessions in particular. As future business cycle GDP occurrences and variations are not easy to detect, governments of affected countries cannot appropriately prepare to react in order to compensate recession implications. Hence, the recession forecasting is still a topic attracting attention of scientists in the field of macroeconomic.

For recession forecasting, leading economic indicators such as a degree of a credit risk, stock price indices, money growth rates, employment and interest rates, or trade yields curves are used as explanatory variables. To detect approaching changes in GDP in this paper we would like to examine a more subtle factor - a factor of human behavior. The main motivation to this work was the last the recession period 2008-2010 with its consequences in later years. Rumors about approaching problems were spreading over internet some time before actual recession could be detected. So our intent was to show if people (statistically) are able to predict upcoming recession. The problem is in a fact, that also information about upcoming problems can cause problems: if workers are afraid of future job losses, they start to save more and substantially decrease consumption. Then decreased consumption implies decreased demand for production, so labor force demand decreases.

We expect that people could indicate if the next recession is approaching. We hypothesize that economic recessions can be predicted with the use of consumer confidence, or, more precisely, that a change in consumer confidence index $(\mathrm{CCl})$ indicate future changes in GDP. Hence, we have chosen a $\mathrm{CCl}$ as an indicator of human behavior. In general, $\mathrm{CCl}$ is used as an indicator of "optimism" of consumers on the state of the economy.

We use $\mathrm{CCl}$ and GDP data from USA for a period 1960-2015. The US data were chosen for their reliability, length (more than 50 years), and because the USA are the leading economy in the world.

The aim of this paper is to examine a statistical relationship between $\mathrm{CCl}$ and GDP in the USA from 1960 to 2015, in an attempt to find whether $\mathrm{CCl}$ can be a suitable predictor of economic growth, or economic recessions respectively. Also short-term dynamics of periods covering US economic recessions is examined. For the study VAR models including Granger causality tests were employed.

The paper is organized as follows: the theoretical background in part 1 is followed by description of data and methods in section 2. Results of long-term dynamics, causality tests and short-term dynamics are covered in parts 3 through 5 ; results are discussed in part 6 , conclusions and list of references ends the article.

\section{Theoretical Background}

As mentioned above, for recession forecasting, leading economic indicators such as a degree of a credit risk, stock price indices, money 
growth rates, employment and interest rates, or trade yields curves are used as explanatory variables. For example, Stock and Watson (1993) used a broad set of 45 economic indicators to predict business cycles, but the performance of their models was rather poor. Estrella and Mishkin (1998) found that the slope of the term structure of U.S. Treasury yields is a good predictor of U.S. economic growth at a horizon up to two years. In the short-term (up to two quarters), stock prices and other macroeconomic indicators were found useful as well. Chauvet and Potter (2005) examined various probit models to find which model is the most useful. Liu and Moench (2014), who also used probit models, found that the Treasury term spread significantly improves predictive power when used with other leading economic indicators at a horizon of one year. See also other recent studies, e.g. Afshar (2007) or Berge (2014).

Prediction of US recessions was studied e.g. in Estrella and Mishkin (1998), Afshar (2007), Kauppi and Saikkonen (2008) or Liu and Moench (2014). Nevertheless, forecasts of economic recessions remain spectacularly unsuccessful. The outbreak of the Great Recession in 2007-2008 caught majority of economists by surprise. Moreover, Ahir and Loungani (2014) point out that from 60 world recessions in the 1990s, only 2 were correctly predicted. Up to date, there is no universally accepted (or successful) method for predicting economic recessions, as economic declines arrive often unexpectedly. Berge (2014) provides some explanation on why recession forecasting is so difficult: although various macroeconomic indicators contain information on business cycle turning points, they vary in their time horizons, so when one indicator signals recession, other indicators may signal no recession. Therefore, researchers must solve the problem how to combine a set of appropriate (non-contradicting) indicators with the desired time horizon of predictions and a suitable mathematical (statistical) model.

As $\mathrm{CCl}$ measures a "mood" of consumers, it can be expected that when $\mathrm{CCl}$ decreases, also consumers spending decreases, and vice versa. This relationship was addressed (and confirmed) by Bram and Ludvigson (1998), Ludvigson (2004), Gelper et al. (2007) or Dees and Brinca (2011). Because consumers spending accounts for around $60-70 \%$ of US
GDP in last decades, see World Bank (2016), $\mathrm{CCl}$ might indirectly affect GDP.

The relationship between $\mathrm{CCl}$ and GDP was examined rather sparsely, see e.g. Afshar (2007), who found Granger causality between a set of consumer measures and real GDP in USA in 1980-2005. Sergeant et al. (2011) focused on Jamaica and Trinidad and Tobago with the result that consumer confidence indices can be useful in modeling GDP. The same conclusion was reached in Kuzmanovič and Sanfey (2012) study of Croatia. More complex paper by Mourougane and Moreno (2002) dealt with larger European countries (Germany, Italy, France, etc.) and concluded that consumer confidence indices might be useful in forecasting real GDP, especially in the short run. Utaka (2003) studied the relationship between $\mathrm{CCl}$ and GDP in Japan, with the result $\mathrm{CCl}$ has a significant effect on GDP in short-term.

\section{Data and the Method}

For the study $\mathrm{CCl}$ time series and GDP time series from 1960 to 2015 from the USA were used. According to OECD (2016), "The CCI is based on households' plans for major purchases and their economic situation, both currently and their expectations for the immediate future. Opinions compared to a "normal" state are collected and the difference between positive and negative answers provides a qualitative index on economic conditions." It should be noted that $\mathrm{CCl}$ provided by OECD is not the same as other consumer confidence indices used in practice, namely The Conference board $\mathrm{CCl}$ (this consumer index is based on surveys on 5,000 US households; questions are focused on current business and employment positions as well as on expected business and employment positions in six month perspective). For more detailed methodology and construction of various consumer confidence indices see Merkle et al. (2003).

The data for the study include:

- Consumer confidence index (CCl) monthly data (seasonally adjusted) from 1960 to 2015: from OECD (2016), quarterly averaged.

- Quarterly real GDP (rGDP) in chained 2009 USD (seasonally adjusted) from 1960 to 2015 : FRED (2016).

The short-term dynamics analysis is focusing on ten-year periods covering main US 


\section{Ekonomie}

recessions. We have chosen four 10-year-long periods:

- The period 1967-1977 covers two shorter recessions (1970-1971 and 1974-1975 recessions).

- The period 1975-1985 covers one longer recession (lasting from 1980 till 1983).

- The period 1995-2005 covers a dot-com bubble and subsequent recession 20012002.

- The last period 2005-2015 covers the recession period 2008-2010, which is still influencing economics in the US.

Both time series for the whole period are provided in Fig. 1.

The main task of this analysis is to compare the dynamics of two time series - in this case time series data of $\mathrm{CCl}$ and rGDP. In general, two non-stationary time series are cointegrated if they tend to move together. From the economists' point of view, they can be tied together, but their mutual bind is not necessary. The necessary condition for cointegration of two time series is the assumption, that each of the series is not stationary with unit root, while some linear combination of the series is stationary.

The standard way how to determine the long-run and short-run relationship between two time series is to:

- check the data series on spurious regressions and possible mutual relationship; in this case simple regression and graphical evaluation is sufficient;

- for both time series, check unit root perform Dickey-Fuller test (or augmented Dickey-Fuller test) in order to check unit roots in both time series;

- perform Dickey-Fuller test on residuals from the simple regression of the two series in

\section{Fig. 1: Time series plot of $\mathrm{CCl}$ and GDP during 1960-2015}
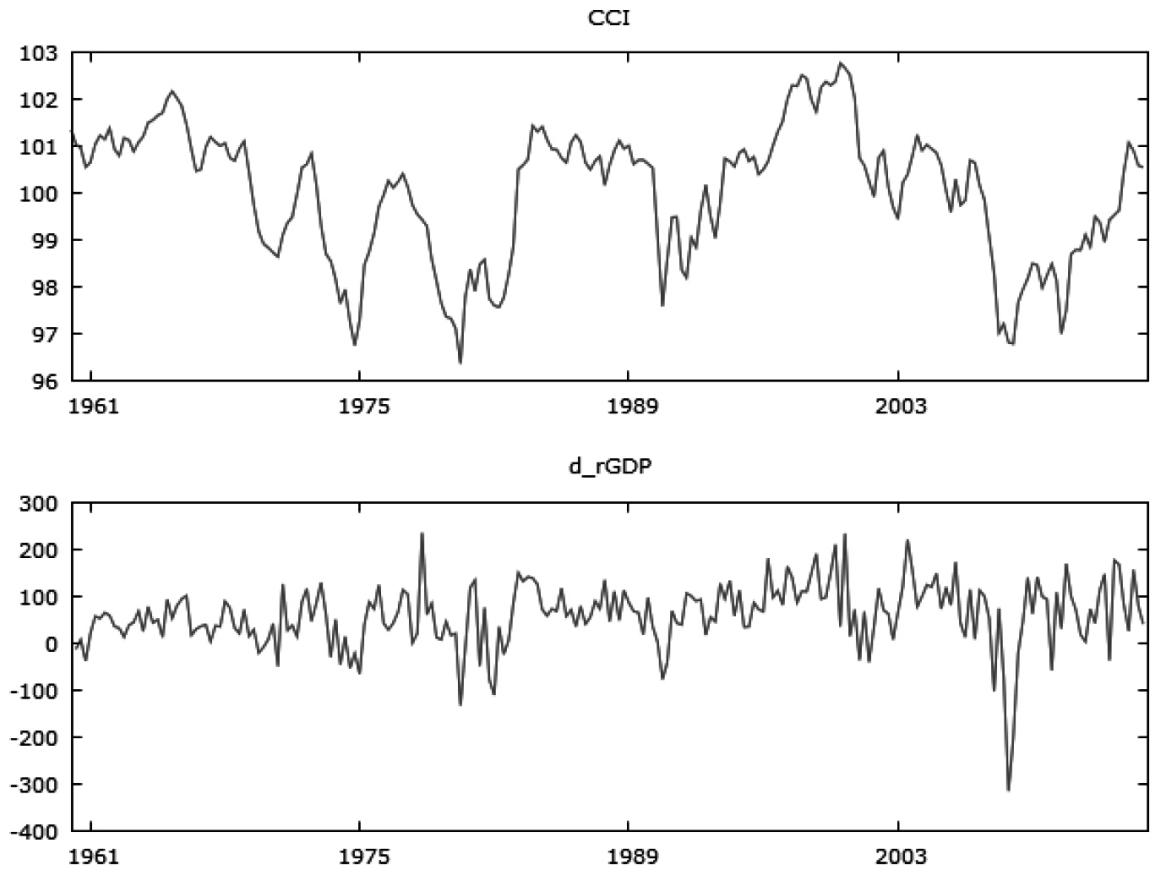
order to reveal the form of the long-term relationship;

- in the case when residuals are stationary, perform the vector error-correction model (VECM); if residuals are not stationary, vector auto-regression (VAR) estimation is sufficient, number of lags in the model is standardly determined by Akaike Information Criterion (Akaike, 1974) or Schwarz-Bayesian information criterion (Schwarz, 1978);

- check for the short-run causality using Granger causality test.

Unit roots are usually tested via the augmented Dickey-Fuller (ADF) test. Number of augmentation terms is standardly chosen by Akaike Information Criterion (AIC), or SchwarzBayesian information criterion (BIC); for example of the model with two augmentation terms:

$$
\begin{aligned}
& \Delta y_{t}=\beta_{0}+\beta_{1} \cdot y_{t-1}+\beta_{2} \cdot \Delta y_{t-1}+ \\
& +\beta_{3} \cdot \Delta y_{t-2}+\varepsilon_{t} .
\end{aligned}
$$

Then the null hypothesis (unit root) is based on test statistics equal to the $t$-ratio of the coefficient:

$$
D F_{t}=\frac{\beta_{1}}{S E\left(\beta_{1}\right)} .
$$

Critical values are given in statistical tables, in the case of the model with two augmentation terms they are equal to -3.44 and -2.87 for $1 \%$ and $5 \%$ level of significance, respectively.

In order to find a long-term dependency between the $\mathrm{CCl}$ and the real GDP time series, the Engle-Granger test was used (Engle and Granger, 1987). In general, this test is divided into two steps: the first step consists of a collection of a residuals from the ordinary regression estimation performed on the variables; as the second step, the DickeyFuller unit root test on collected residuals is performed. Co-integration occurs if errors do not have a unit root. In the case of longterm relationship, if residuals are stationary, then to perform the vector error-correction model (VECM) is appropriate; if residuals are not stationary, vector autoregression (VAR) estimation is sufficient.
In the case of short-run relations between two time series, the Granger causality test is the standard statistical tool to study a short-run causality. This test is constructed such that it reveals mutual movement of time series through time changes, not literally "causality" in a sense that one time series is a cause of the second one; the meaning of the expression "Granger cause" is equivalent to the expression "precede" more than "cause". In a case of stationarity of two time series $X$ and $Y$, Granger causality is examined via the vector autoregressive (VAR) model of the following form:

$$
\begin{aligned}
& Y_{t}=\beta_{0}+\beta_{1} Y_{t-1}+\beta_{2} Y_{t-2}+\ldots+ \\
& +\beta_{p} Y_{t-p}+\gamma_{1} X_{t-1}+\gamma_{2} X_{t-2}+\ldots+ \\
& +\gamma_{q} X_{t-q}+\varepsilon_{t}
\end{aligned}
$$

This test is based on comparison of unrestricted and restricted VAR models, and is of the form (Wei, 1994):

$$
\begin{aligned}
& F=\frac{\left(R S S_{\text {restricted }}-R S S_{\text {unrestricted }}\right) / M}{R S S_{\text {unrestricted }} /(N-K-1)} \approx \\
& \approx F(M, N-K-1)
\end{aligned}
$$

where RSS denotes the sum of squared residuals, $K$ is the number of unrestricted model slope coefficients, $M$ equals the number of slope coefficients eliminated in the restricted equation, and $N$ is the number of observations. Restricted estimated model usually contains only lagged variables of $Y$ as explanatory variables. Critical values of F-distribution are given in statistical tables, p-levels are standard outcomes of most statistical software packages.

\section{Long-Term Relation}

We start with a simple linear regression between $\mathrm{CCl}$ and GDP. We expect that changes in GDP are dependent on movement of $\mathrm{CCl}$; so the expected model takes the following form:

$$
\Delta G D P_{t}=\beta_{0}+\beta_{1} C C I_{t}+\varepsilon_{t}
$$

For illustration, the $X-Y$ scatter graph of the two variables together with a regression line and regression equation is depicted in Fig. 2. The regression equation is of the form:

$$
\Delta G D P_{t}=-2085.3+21.5 C C I_{t}+\varepsilon_{t}
$$




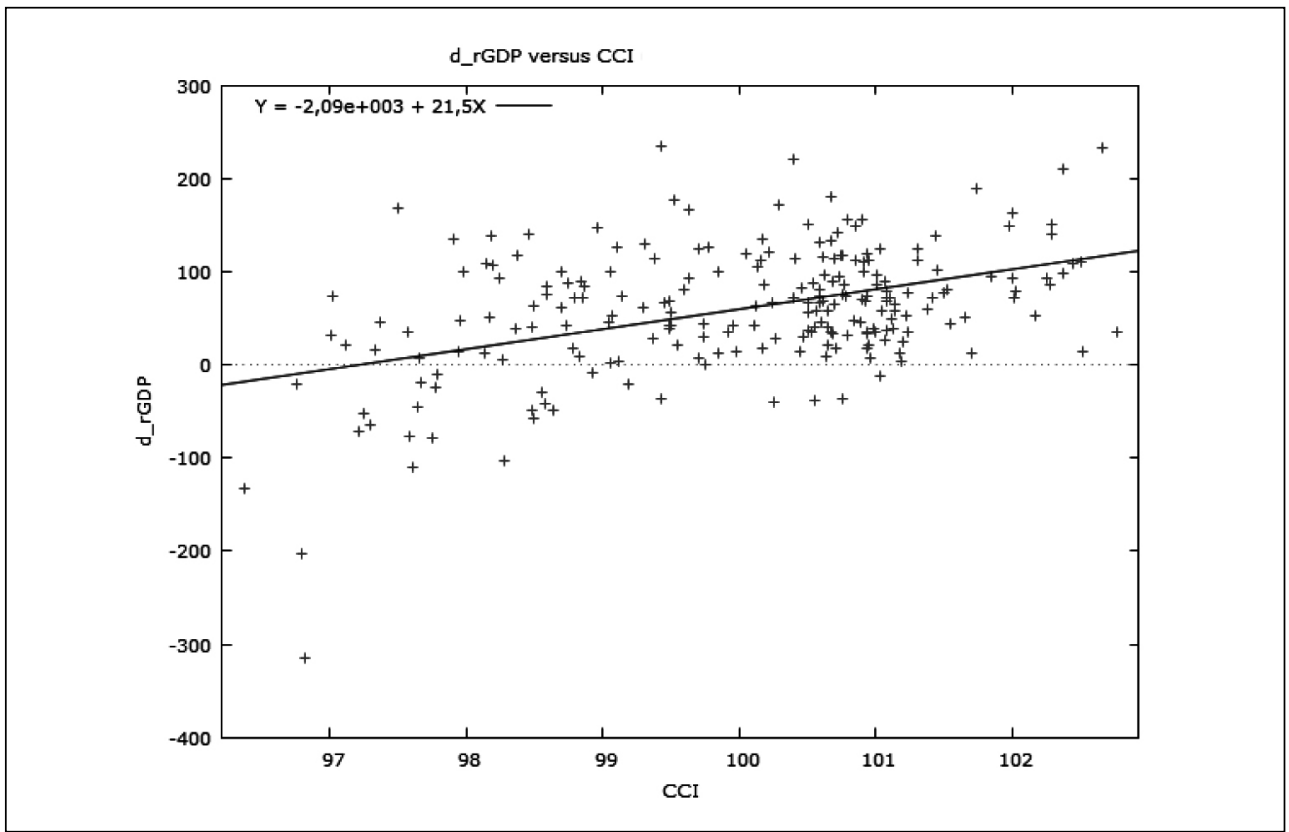

The coefficient of determination $R^{2}=0.194$ $R^{2}=0.194$, and the Durbin-Watson statistics reach the value of 1.49 .

Unit roots were tested via the augmented Dickey-Fuller (ADF) test with two augmentation terms. Number of augmentation terms was chosen with respect to results of the Akaike Information Criterion (AIC), as well as the Schwarz-Bayesian information criterion (BIC).

$$
\begin{aligned}
& \Delta y_{t}=\beta_{0}+\beta_{1} \cdot y_{t-1}+\beta_{2} \cdot \Delta y_{t-1}+ \\
& +\beta_{3} \cdot \Delta y_{t-2}+\varepsilon_{t}
\end{aligned}
$$

Results of the ADF test with asymptotic $p$-values for $\mathrm{CCl}$ and real GDP (rGDP) indices are given in Tab. 1; the hypothesis of unit root cannot be rejected for both variables at a $5 \%$ level of significance.

Results of the ADF test with asymptotic $p$-values for first differences in both variables (d_CCl and d_rGDP) indices are given in Tab. 2; the hypothesis of unit root can be rejected for both variables at a $5 \%$ level of significance.
The necessary condition for cointegration relation of the two time series is fulfilled: that each of the series is not stationary with unit root, while their first differences are stationary.

The next step is to determine the long-term relation between the time series. However, before the analysis it is necessary to stabilize rGDP time series. In order to stabilize a real GDP time series (exclude its trend) we added a time variable into the regression equation; hence the regression equation is of the form:

$$
\begin{aligned}
& r G D P_{t}=-8695.76+105.722 C C I_{t}+ \\
& +62.963 \operatorname{TIME}_{t}+\varepsilon_{t}
\end{aligned}
$$

The coefficient of determination $R^{2}=0.979$ and the Durbin-Watson statistics reach the value of 0.016 .

In the second step, the ADF test on residuals was performed. Results of the estimation for one augmentation term are given in Tab. 3 .

The results indicate that the cointegration in the whole data set is not present, the vector autoregression model (VAR) to describe the 
Tab. 1: Results of augmented Dickey-Fuller tests based on equation (7)

\begin{tabular}{l|r|r|r|r|r|r} 
& $\boldsymbol{\beta}_{0}$ & $\boldsymbol{\beta}_{1}$ & $\boldsymbol{\beta}_{\mathbf{2}}$ & $\boldsymbol{\beta}_{\mathbf{3}}$ & $\boldsymbol{D F}_{\boldsymbol{t}}$ & \multicolumn{1}{c}{$\boldsymbol{p}$-value } \\
\hline $\mathrm{CCl}$ & 6.3256 & -0.0633 & 0.3173 & -0.1510 & -2.853 & 0.0534 \\
\hline rGDP & 21.3560 & 0.0012 & 0.3040 & 0.1613 & 1.149 & 0.9979 \\
\hline
\end{tabular}

Source: own calculations

\section{Tab. 2: Results of augmented Dickey-Fuller tests based on equation (7)}

\begin{tabular}{l|c|c|c|c|c|c} 
& $\boldsymbol{\beta}_{0}$ & $\boldsymbol{\beta}_{\boldsymbol{1}}$ & $\boldsymbol{\beta}_{\mathbf{2}}$ & $\boldsymbol{\beta}_{\mathbf{3}}$ & $\boldsymbol{D} \boldsymbol{F}_{\boldsymbol{t}}$ & p-value \\
\hline d_CCl & 0.0006 & -0.7365 & 0.0678 & -0.1809 & -7.350 & $3.61^{*} 10^{-11}$ \\
\hline d_rGDP & 31.9440 & -0.5218 & -0.1665 & 0.0019 & -6.356 & $1.59^{*} 10^{-8}$ \\
\hline
\end{tabular}

Tab. 3: $\begin{aligned} & \text { Results of the ADF test performed on residuals from equation (8), } \\ & \text { one augmentation term }\end{aligned}$

\begin{tabular}{|c|c|c|c|c|}
\hline & $\boldsymbol{\beta}_{0}$ & $\beta_{1}$ & $\beta_{2}$ & $D F_{t}$ \\
\hline rGDP & -2.056 & -0.014 & 0.242 & -1.7 \\
\hline
\end{tabular}

Source: own calculations

\section{Tab. 4: Results of VAR model based on equation (9)}

\begin{tabular}{l|r|r|r|r|r|r} 
& \multicolumn{1}{|c|}{$\boldsymbol{\beta}_{\boldsymbol{0}}$} & \multicolumn{1}{c|}{$\boldsymbol{\beta}_{\boldsymbol{1}}$} & \multicolumn{1}{c|}{$\boldsymbol{\beta}_{\mathbf{2}}$} & \multicolumn{1}{c|}{$\boldsymbol{\beta}_{\mathbf{3}}$} & \multicolumn{1}{c}{$\boldsymbol{\beta}_{\mathbf{4}}$} & \multicolumn{1}{c}{$\boldsymbol{\beta}_{\mathbf{5}}$} \\
\hline Coefficients & $-1,614.86$ & 1.1379 & -0.1561 & 41.1794 & -24.4235 & 1.3505 \\
\hline t-ratio & -4.865 & 16.59 & -2.313 & 4.703 & -2.862 & -3.103 \\
\hline p-value & $2.21 * 10^{-6}$ & $2.11^{*} 10^{-40}$ & 0.0217 & $4.51^{*} 10^{-6}$ & 0.0046 & 0.0022 \\
\hline
\end{tabular}

Source: own calculations

data is sufficient. Number of lags in VAR model was set to be 2, as determined by Akaike Information Criterion (AIC) as well as SchwartzBayes Criterion. The model is of the form:

$$
\begin{aligned}
& r G D P_{t}=\beta_{0}+\beta_{1} r G D P_{t-1}+\beta_{2} r G D P_{t-2}+ \\
& +\beta_{3} C C I_{t-1}+\beta_{4} C C I_{t-2}+\beta_{5} T_{M} E_{t}+\varepsilon_{t}
\end{aligned}
$$

Results of estimations from equations (9) are given in Tab. 4. Estimated coefficient $\beta_{2}$ is statistically significant at $5 \%$ level of significance; all other regression coefficients are statistically significant at $1 \%$ level of significance. The value of the coefficient of determination $R^{2}=0.9998$, Durbin-Watson statistics is equal to 2.038 .
Results indicate that real GDP variable is highly dependent on lagged $\mathrm{CCl}$ variables. Impulse-response function of real GDP on a unit shock of $\mathrm{CCl}$ shows an increase in real GDP variable not opposed by any immediate process (Fig. 3).

\section{Causality Relationship between GDP and CCI Time Series}

As mentioned in previous text, we hypothesize that the Consumer Confidence Index has a short-term relationship with changes in real GDP. Moreover we expect that changes in $\mathrm{CCl}$ can indicate or "predict" real GDP changes in next periods. In order to reveal this kind 


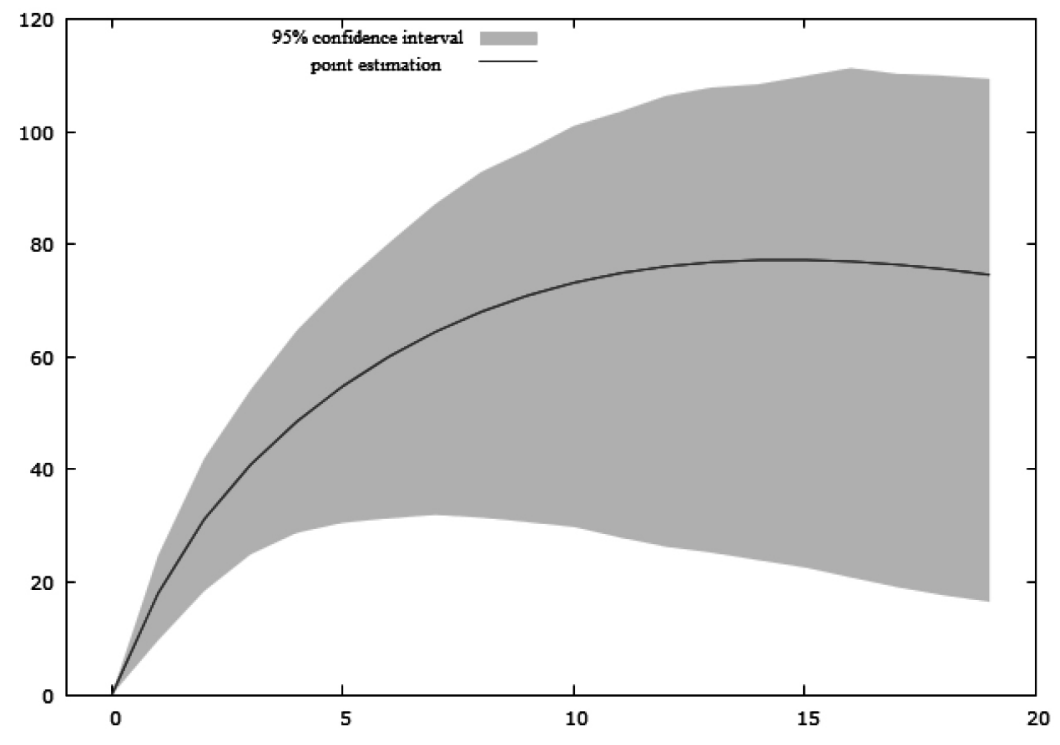

Source: own calculations

of causality, the Granger causality test was used. The unrestricted model for this analysis was taken the VAR model from equation (6), the restricted model is of a form:

$$
\begin{aligned}
& r G D P_{t}=\beta_{0}+\beta_{1} r G D P_{t-1}+ \\
& +\beta_{2} r G D P_{t-2}+\beta_{5} T{ } E_{t}+\varepsilon_{t}
\end{aligned}
$$

In general, the Granger causality test is constructed such that it reveals mutual movement of time series through time changes, not literally "causality" in a sense that one time series is a cause of the second one; the meaning of the expression "Granger cause" is equivalent to the expression "precede" more than "cause". Results for comparisons (2 lags with trend as determined by AIK) of changes in real GDP and $\mathrm{CCl}$ developments (for completeness also the reverse causality relation was tested) are given in Tab. 5 with values of F-test and p-values;

Results indicate that changes in $\mathrm{CCl}$ precede changes in real GDP by two time periods, in this case that means 6 months.
Thus changes in $\mathrm{CCl}$ can be used as predictor of short-run trend in real GDP movement.

\section{Short-Term Dynamics}

The short-term dynamics analysis is focusing on ten-year periods covering main US recessions. We have chosen four 10-year-long periods: the period 1967-1977 covers two shorter recessions (1970-1971 and 1974-1975 recessions), the period 1975-1985 covers one longer recession (lasting from 1980 till 1983), the period 19952005 covers a dot-com bubble and subsequent recession 2001-2002, and the last period 20052015 covers the recession period 2008-2010, which is still influencing economics in the US. For all the mentioned periods we examined Granger causality between the series.

\subsection{The Period from 1967 till 1977}

The period 1967-1977 covers two main decreases in real GDP growth. The first decrease appeared during 1970-1971, the second followed in 1974-1975 (Fig. 4). 


\begin{tabular}{c|c|c|c} 
Statement & F test & p-value & Result for $\boldsymbol{\alpha}=\mathbf{0 . 0 5}$ \\
\hline "Changes in CCI Granger cause changes in real GDP" & 18.78400 & 0.0000 & Yes \\
\hline "Changes in real GDP Granger cause changes in CCl" & 0.95931 & 0.3848 & No
\end{tabular}

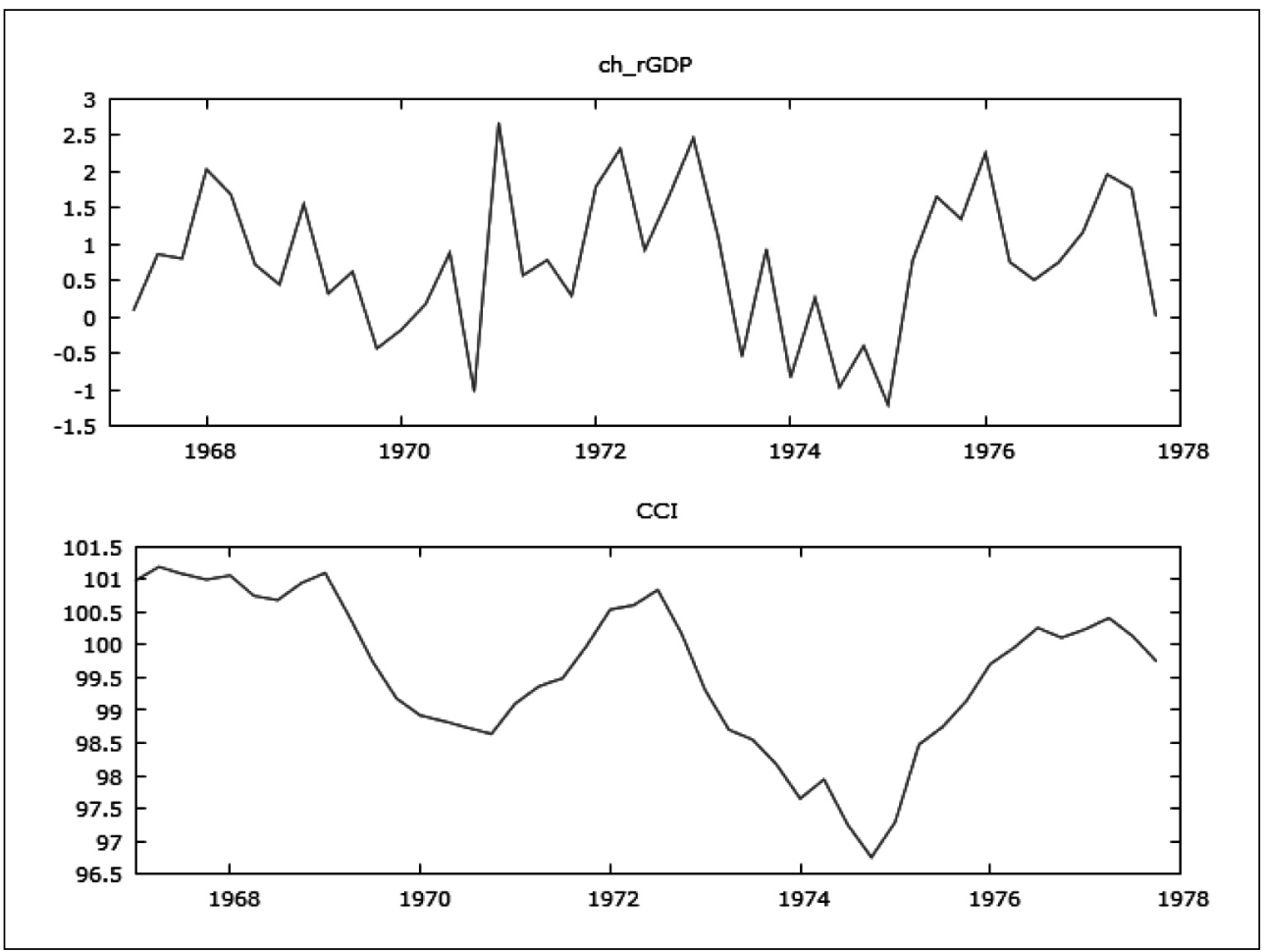

Source: own calculations

Tab. 6: Results of augmented Dickey-Fuller tests with one augmentation term

\begin{tabular}{l|l|l|r|r|r} 
& $\boldsymbol{\beta}_{\boldsymbol{0}}$ & $\boldsymbol{\beta}_{\boldsymbol{1}}$ & $\boldsymbol{\beta}_{\mathbf{2}}$ & $\boldsymbol{D F}_{\boldsymbol{t}}$ & \multicolumn{1}{c}{$\boldsymbol{p}$-value } \\
\hline $\mathrm{CCl}$ & 12.1972 & -0.1228 & 0.5523 & -2.542 & 0.1055 \\
\hline rGDP & 44.5032 & -0.0030 & 0.2713 & -0.170 & 0.9398 \\
\hline \multicolumn{4}{|r}{}
\end{tabular}


Results of the ADF test with asymptotic $p$-values for $\mathrm{CCl}$ and rGDP indices during the period of 1967-1977 are given in Tab. 6; the hypothesis of unit root cannot be rejected for both variables at a $5 \%$ level of significance.

In order to find a dependency between the $\mathrm{CCl}$ and the real GDP time series, the Engle-Granger test was used with the result that the cointegration in the whole data set is not present, the vector autoregression model (VAR) to describe the data is sufficient ( $p$-value of Dickey-Fuller test on residuals of regression equation is equal to 0.8812). Number of lags in VAR model was set to be 2, as determined by AIC. The model is of the form:

$$
\begin{aligned}
& r G D P_{t}=\beta_{0}+\beta_{1} r G D P_{t-1}+\beta_{2} r G D P_{t-2}+ \\
& +\beta_{3} C C I_{t-1}+\beta_{4} C C I_{t-2}+\varepsilon_{t}
\end{aligned}
$$

Results of estimations from equations (11) are given in Tab. 7. Estimated coefficient $\beta_{2}$ is not statistically significant; all other regression coefficients are statistically significant at 5\% level of significance. The value of the coefficient of determination $R^{2}=0.992$, Durbin-Watson statistics is equal to 2.06 .

Tab. 7: Results of VAR model based on equation (11)

\begin{tabular}{l|r|r|r|r|r} 
& \multicolumn{1}{|c|}{$\boldsymbol{\beta}_{\mathbf{0}}$} & \multicolumn{1}{c|}{$\boldsymbol{\beta}_{\boldsymbol{1}}$} & \multicolumn{1}{c|}{$\boldsymbol{\beta}_{\mathbf{2}}$} & \multicolumn{1}{c}{$\boldsymbol{\beta}_{\mathbf{3}}$} & \multicolumn{1}{c}{$\boldsymbol{\beta}_{\mathbf{4}}$} \\
\hline Coefficients & $-2,288.41$ & 0.9338 & 0.0891 & 59.8544 & -37.5968 \\
\hline t-ratio & 894.996 & 0.1674 & 0.1749 & 16.9836 & 15.8488 \\
\hline p-value & 0.0094 & $2.33^{*} 10^{-6}$ & 0.6134 & 0.0011 & 0.0232 \\
\hline
\end{tabular}

Source: own calculations

Tab. 8: Results of Granger causality tests

\begin{tabular}{c|r|r|c} 
Statement & F test & \multicolumn{1}{c|}{ p-value } & Result for $\boldsymbol{\alpha}=\mathbf{0 . 0 5}$ \\
\hline “Changes in CCI Granger cause changes in real GDP" & 7.5480 & 0.0018 & Yes \\
\hline "Changes in real GDP Granger cause changes in CCl" & 0.8528 & 0.4344 & No \\
\hline \multicolumn{2}{|c}{ Source: own calculations }
\end{tabular}

Results of Granger causality tests (2 lags) of changes in real GDP and $\mathrm{CCl}$ developments are given in Tab. 8 .

Results indicate that changes in $\mathrm{CCl}$ precede changes in real GDP by two time periods, in this case that means 6 months.

\subsection{The Period from 1975 till 1985}

The period 1975-1985 covers one longer recession (lasting from 1980 till 1983), both CCI and real GDP changes are depicted in Fig. 5.

Results of augmented Dickey-Fuller tests indicate that the hypothesis of unit root cannot be rejected for both real GDP and $\mathrm{CCl}$ variables at a $5 \%$ level of significance (asymptotic p-values for augmented Dickey-Fuller test for two augmentation terms without trend for both
$\mathrm{CCl}$ and real GDP variables are 0.5576 and 0.9445 , respectively).

In order to find a dependency between the $\mathrm{CCl}$ and the real GDP time series for this time period, the Engle-Granger test was used with the result that the cointegration in the whole data set is not present, the vector autoregression model (VAR) to describe the data is sufficient ( $p$-value of Dickey-Fuller test on residuals of regression equation is equal to 0.9295 ).

Number of lags in VAR model was set to be 2 , as determined by AIC. The model is of the form:

$$
\begin{aligned}
& r G D P_{t}=\beta_{0}+\beta_{1} r G D P_{t-1}+\beta_{2} r G D P_{t-2}+ \\
& +\beta_{3} C C I_{t-1}+\beta_{4} C C I_{t-2}+\varepsilon
\end{aligned}
$$




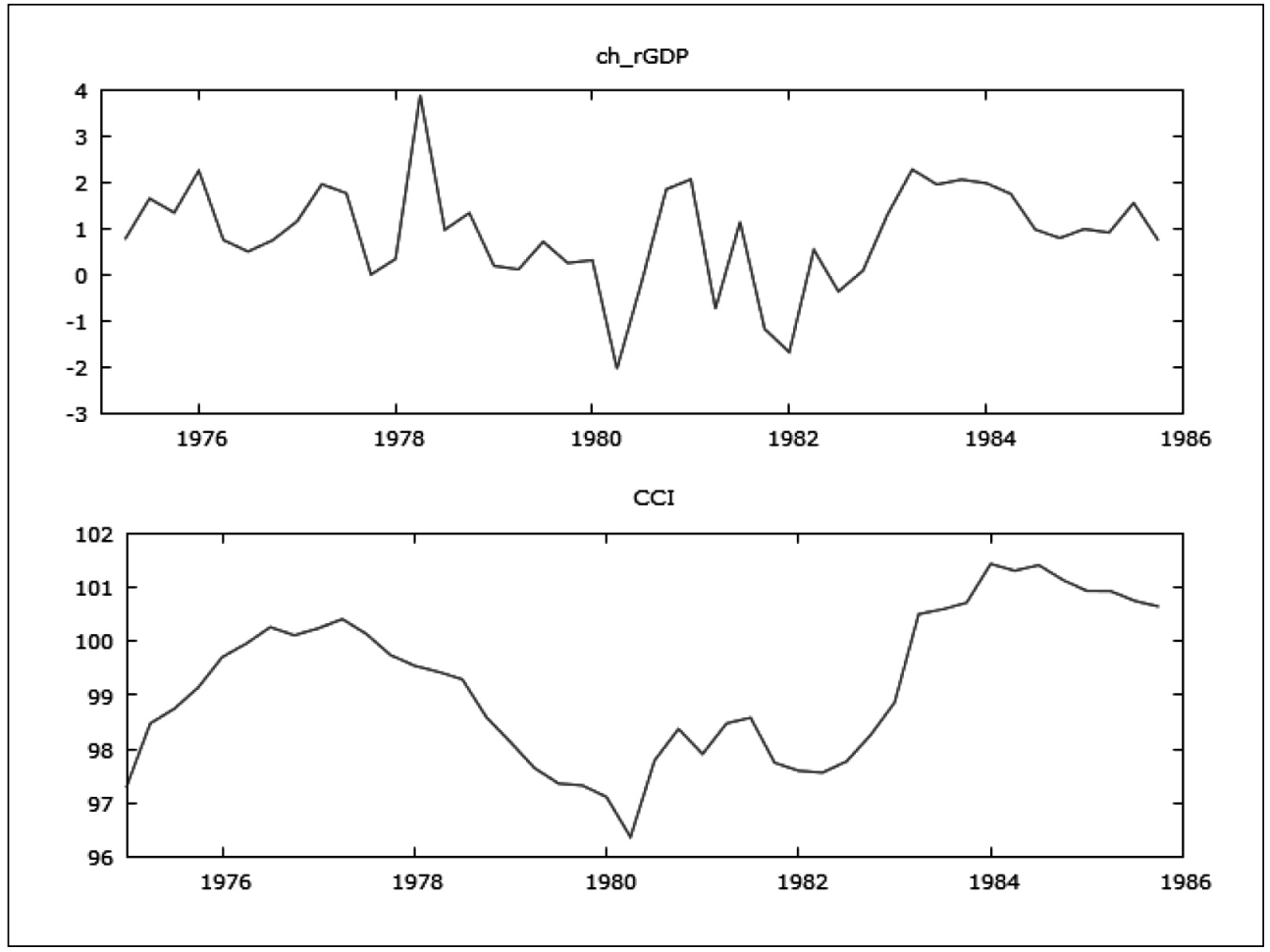

Source: own calculations

Results of estimation from equation (12) are given in Tab. 9. Estimated coefficient $\beta_{2}$ is not statistically significant; all other regression coefficients are statistically significant at $5 \%$ level of significance. The value of the coefficient of determination $R^{2}=0.991$, Durbin-Watson statistics is equal to 1.89 .

The model is very close to the model describing previous studied period of 19671977. Results of Granger causality tests (2 lags) of changes in real GDP and $\mathrm{CCl}$ developments are given in Tab. 10.

Results indicate that changes in $\mathrm{CCl}$ precede changes in real GDP by two time periods, in this case that means 6 months.

\subsection{The Period from 1995 till 2005}

The period 1995-2005 covers a dot-com bubble and a subsequent recession 2001-2002; both $\mathrm{CCl}$ and real GDP changes are depicted in Fig. 6 .

\section{Tab. 9: Results of VAR model based on equation (12)}

\begin{tabular}{l|r|r|r|r|r} 
& \multicolumn{1}{|c|}{$\boldsymbol{\beta}_{0}$} & \multicolumn{1}{c|}{$\boldsymbol{\beta}_{\boldsymbol{1}}$} & \multicolumn{1}{c|}{$\boldsymbol{\beta}_{\mathbf{2}}$} & \multicolumn{1}{c}{$\boldsymbol{\beta}_{\mathbf{3}}$} & \multicolumn{1}{c}{$\boldsymbol{\beta}_{\mathbf{4}}$} \\
\hline Coefficients & $-2,298.23$ & 0.9516 & 0.0410 & 80.8316 & -56.6337 \\
\hline p-value & 0.0071 & $6.17^{*} 10^{-7}$ & 0.7958 & 0.0001 & 0.0032 \\
\hline
\end{tabular}

Source: own calculations 


\section{Ekonomie}

\section{Tab. 10:}

Results of Granger causality tests

\begin{tabular}{c|r|r|c} 
Statement & \multicolumn{1}{|c|}{ F test } & \multicolumn{1}{c|}{ p-value } & Result for $\boldsymbol{\alpha = 0 . 0 5}$ \\
\hline "Changes in CCI Granger cause changes in real GDP" & 10.1830 & 0.0003 & Yes \\
\hline "Changes in real GDP Granger cause changes in CCl" & 0.2832 & 0.7550 & No \\
\hline
\end{tabular}

Source: own calculations

\section{Fig. 6: Time series plot of $\mathrm{CCl}$ and quarterly GDP changes during the period of 1995-2005}

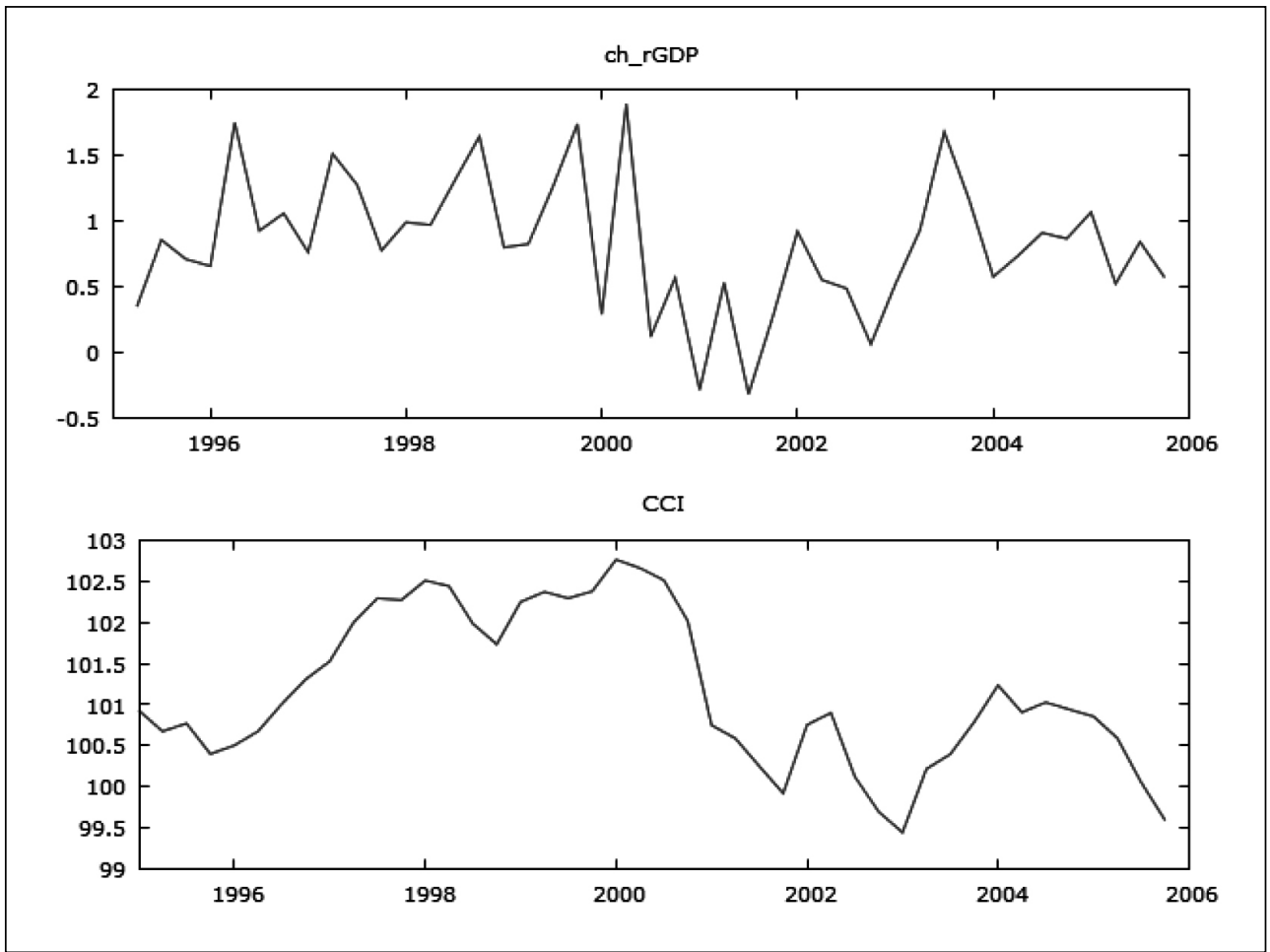

Source: own calculations

Results of augmented Dickey-Fuller tests indicate that the hypothesis of unit root cannot be rejected for both real GDP and $\mathrm{CCl}$ variables at a $5 \%$ level of significance (asymptotic p-values for augmented Dickey-Fuller test for two augmentation terms without trend for both $\mathrm{CCl}$ and real GDP variables are 0.5672 and 0.8303 , respectively).

In order to find a dependency between the $\mathrm{CCl}$ and the real GDP time series for this time period, the Engle-Granger test was used with the result that the cointegration in the whole data set is not present, the VAR model to describe the data is sufficient ( $p$-value of Dickey-Fuller test on residuals of regression equation is equal to 0.7266 ). Number of lags in VAR model was set to be 2 , as determined by AIC. The model is, as in previous cases, of the form:

$$
\begin{aligned}
& r G D P_{t}=\beta_{0}+\beta_{1} r G D P_{t-1}+\beta_{2} r G D P_{t-2}+ \\
& \beta_{3} C C I_{t-1}+\beta_{4} C C I_{t-2}+\varepsilon_{t}
\end{aligned}
$$




\section{Tab. 11: Results of VAR model based on equation (13)}

\begin{tabular}{l|r|r|r|r|r} 
& \multicolumn{1}{|c|}{$\boldsymbol{\beta}_{\boldsymbol{0}}$} & \multicolumn{1}{c|}{$\boldsymbol{\beta}_{\boldsymbol{1}}$} & \multicolumn{1}{c|}{$\boldsymbol{\beta}_{\mathbf{2}}$} & \multicolumn{1}{c}{$\boldsymbol{\beta}_{\mathbf{3}}$} & \multicolumn{1}{c}{$\boldsymbol{\beta}_{\mathbf{4}}$} \\
\hline Coefficients & -224.2050 & 0.9791 & 0.0192 & 54.0905 & -50.6356 \\
\hline p-value & 0.8471 & $1.4^{*} 10^{-6}$ & 0.9116 & 0.0492 & 0.0534 \\
\hline
\end{tabular}

Source: own calculations

\section{Tab. 12: Results of Granger causality tests}

\begin{tabular}{c|r|r|c} 
Statement & \multicolumn{1}{|c|}{ F test } & \multicolumn{1}{c|}{ p-value } & Result for $\boldsymbol{\alpha}=\mathbf{0 . 0 5}$ \\
\hline "Changes in CCl Granger cause changes in real GDP" & 2.1276 & 0.1335 & No \\
\hline "Changes in real GDP Granger cause changes in CCl" & 4.3650 & 0.0199 & \multicolumn{1}{c}{ Yes } \\
\hline
\end{tabular}

Source: own calculations

Results of estimations from equations (13) are given in Tab. 11. Estimated coefficient $\beta_{2}$ is not statistically significant; all other regression coefficients are statistically significant at $10 \%$ level of significance. The value of the coefficient of determination $R^{2}=0.998$, Durbin-Watson statistics is equal to 2.11 .
Results of Granger causality tests (2 lags) of changes in real GDP and $\mathrm{CCl}$ developments are given in Tab. 12.

Results indicate that changes in real GDP precede changes in $\mathrm{CCl}$ by two time periods, in this case that means 6 months.
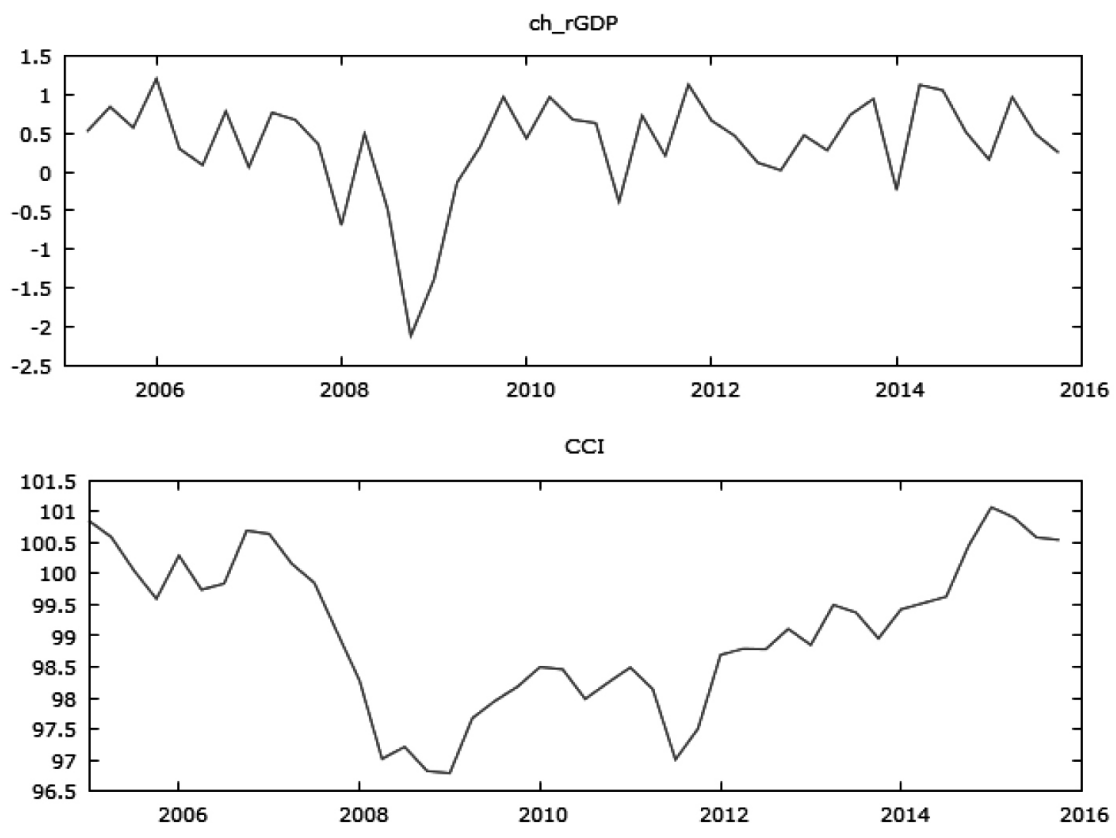


\subsection{The Period from 2005 till 2015}

The period 2005-2015 covers the recession period 2008-2010, which is still influencing economics in the US; both $\mathrm{CCl}$ and real GDP changes are depicted in Fig. 7.

Results of augmented Dickey-Fuller tests indicate that the hypothesis of unit root cannot be rejected for both real GDP and $\mathrm{CCl}$ variables at a $5 \%$ level of significance (asymptotic $\mathrm{p}$-values for augmented Dickey-Fuller test for two augmentation terms without trend for both $\mathrm{CCl}$ and real GDP variables are 0.5820 and 0.9662 , respectively).

In order to find a dependency between the $\mathrm{CCl}$ and the real GDP time series for this time period, the Engle-Granger test was used with the result that the cointegration in the whole data set is not present, the vector autoregression model (VAR) to describe the data is sufficient ( $p$-value of Dickey-Fuller test on residuals of regression equation is equal to 0.9470). According to AIC the number of lags should be 2; however the VAR model with two lag variables led to not statistically significant regression coefficients. Hence, number of lags in VAR model was set to be 1 , as determined by Schwartz-Bayes Criterion. The model is of the form:

$$
r G D P_{t}=\beta_{0}+\beta_{1} r G D P_{t-1}+\beta_{2} C C I_{t-1}+\varepsilon_{t}
$$

Results of estimations from equations (14) are given in Tab. 13; all regression coefficients are statistically significant at $5 \%$ level of significance. The value of the coefficient of determination $R^{2}=0.98$, Durbin-Watson statistics is equal to 1.45 .

Results of Granger causality tests (1 lag) of changes in real GDP and $\mathrm{CCl}$ developments are given in Tab. 14 .

\section{Tab. 13: Results of VAR model based on equation (14)}

\begin{tabular}{l|r|r|r} 
& \multicolumn{1}{|c|}{$\boldsymbol{\beta}_{0}$} & \multicolumn{1}{|c|}{$\boldsymbol{\beta}_{\boldsymbol{1}}$} & \multicolumn{2}{c}{$\boldsymbol{\beta}_{\mathbf{2}}$} \\
\hline Coefficients & $-3,004.1400$ & 0.9985 & 31.1085 \\
\hline p-value & 0.0128 & $1.7^{*} 10^{-34}$ & 0.0141 \\
\hline
\end{tabular}

Source: own calculations

\section{Tab. 14: Results of Granger causality tests}

\begin{tabular}{c|r|r|c} 
Statement & \multicolumn{1}{|c|}{ F test } & \multicolumn{1}{c|}{ p-value } & Result for $\boldsymbol{\alpha}=\mathbf{0 . 0 5}$ \\
\hline "Changes in CCl Granger cause changes in real GDP" & 6.5936 & 0.0141 & Yes \\
\hline "Changes in real GDP Granger cause changes in CCl" & 1.7569 & 0.1925 & No \\
\hline
\end{tabular}

Source: own calculations

Results indicate that changes in real GDP precede changes in $\mathrm{CCl}$ by one time period, in this case that means 3 months. This result is different from previous results.

\section{Discussion}

The aim of the paper was to examine whether Consumer Confidence Index from OECD databases can be a suitable predictor of GDP growth, and economic recessions in particular for the US data from 1960 to 2015. Similar study has tried to reveal the relationship between $\mathrm{CCl}$ and GDP in Japan, with the optimistic result that $\mathrm{CCl}$ has a significant effect on GDP (Utaka, 2003). We have chosen longer time period than Afshar (2007), in order to determine if, in the case of developed economy, there is a systematic relation between the two variables.

We found that in the long-term, GDP dependence on $\mathrm{CCl}$ can be modelled by a VAR model with two lags and time trend. Impulseresponse function of the respective process showed that an increase in real GDP variable is not opposed by any immediate process. This result is also consistent with results of Granger causality test, which determined that $\mathrm{CCl}$ 
precedes GDP by 2 periods (6 months). As for short-term dynamics (lasting 10 years) applied to four periods with economic recessions in the USA, it was found that in two periods beginning in 1967 and 1975 respectively, CCl Granger caused GDP with a lag of 6 months. The period covering "dot-com bubble" recession Granger causality was opposite, as GDP caused $\mathrm{CCl}$ with a lag of 6 months. More importantly, the last examined period covering the Great Recession; it was found $\mathrm{CCl}$ Granger causes GDP again with a lag of 3 months.

These result support our expectations that changes in consumer confidence (consumer "mood") cause changes in consumer spending, which in turn influence GDP with a lag of 3 or 6 months. In four out of 5 examined periods, changes in $\mathrm{CCl}$ preceded changes in GDP as expected. The only exception was the period of the so called "dot-com bubble", when changes in GDP preceded changes in $\mathrm{CCl}$. This recession came unexpectedly as a consequence of the downfall of many Internet firms and their stock values after a decade of strong growth. The rise of the so called "new-economy" associated with Internet was a new phenomenon never experienced before. No one knew where the "ceiling" of the growth of this sector might be until its dramatic decline in the early 2000s, which had to be surprising both for firms and investors. Therefore, causes of this recession were different from causes of other examined recessions, where confidence of consumers played more important role.

These results are consistent with similar research of Mourougane and Moreno (2002) on the set of EU countries, who found, that in general confidence indicators could be useful indicators to forecast real GDP growth; however they are unsatisfactory while dealing with nonsystematic shock (in their study represented for example by reunification of Germany). Much more optimistic results were presented by Afshar (2007) and Utaka, (2003) on US, and Japan data sets, respectively. Similar results, were reached in Kuzmanovič and Sanfey's (2012) study of Croatia, as well as in Sergeant et al. (2011), who focused on Jamaica and Trinidad and Tobago. Both studies recommend take $\mathrm{CCl}$ as one of several possible indicators in predicting future GDP changes.

\section{Conclusions}

Our study was focused on determination of a relation between Consumer Confidence index $(\mathrm{CCl})$, and real GDP. We expected that a change in $\mathrm{CCl}$ indicate future changes in GDP. We decided to choose a long-term data set from a developed economy in order to approve or to reject expected relation. Obtained results can later serve as a benchmark for similar studies on more volatile data sets from dynamically developing countries as well as data from small and open economies.

Even though recent similar studies from different data were quite optimistic, we concluded that even though our results indicate that $\mathrm{CCl}$ can be considered a suitable predictor of economic growth at least for the USA data, the short-term estimations may show deviations from long-term trend. These deviations can be caused by nonsystematic shock. Further research may focus on a construction of model with $\mathrm{CCl}$ and others variables (e.g. leading economic indicators), in order to increase the predictive power of the model.

This paper was supported by the Ministry of Education, Youth and Sports within the Institutional Support for Long-term Development of a Research Organization in 2016.

\section{References}

Akaike, H. (1974). A new look at the statistical model identification. IEEE Transactions on Automatic Control, 19(6), 716-723. doi:10.1109/ TAC.1974.1100705.

Ahir, Loungani. (2014). Can economists forecast recessions? Some evidence from the Great Recession. Retrieved from: https://forecasters.org/wp-content/uploads/ PLoungani_OracleMar2014.pdf.

Afshar, T. (2007). Stock Return, Consumer Confidence, Purchasing Manager's Index and Economic Fluctuations. Journal of Business and Economic Research, 5(8), 97-106.

Berge, T. (2014). Predicting recessions with leading indicators: Model averaging and Selection over the Business Cycle [Research Working Papers, 13-05]. Federal Reserve Bank of Kansas City.

Bram, J., \& Ludvigson, S. (1998). Does Consumer Confidence Forecast Household Expenditure? A Sentiment Index Horse Ride. FRBNY Economic Policy Review, 59-78. 
Chauvet, M., \& Potter, S. (2005). Forecasting recessions using the yield curve. Journal of Forecasting, 24(2), 77-103. doi:10.1002/for.932.

Dees, S., \& Brinca, P. S. (2011). Consumer Confidence as a Predictor of Consumption Spending: Evidence for the United States and the Euro Area [Working Paper Series, No. 1349]. European Central Bank.

Engle, R. F., \& Granger, C. W. J. (1987). Co-Integration and Error Correction: Representation, Estimation, and Testing. Econometrica, 55(2), 251-276. doi:00129682(198703)55:2<251:CAECRE>2.0.CO;2-T.

Estrella, A., \& Mishkin, F. S. (1998). Predicting U.S. recessions: Financial variables as leading indicators. The Review of Economics and Statistics, 80(1), 45-61.

FRED. (2016). Federal Reserve Economic Data. Federal Reserve Bank of St. Louis.

Gelper, S., Lemmens, A., Croux, C., \& Leuven, K. U. (2007). Consumer sentiment and consumer spending: decomposing Granger causal relationship in the time domain. Applied Economics, 39(1), 1-11. doi:10.1080/00036840500427791.

Kauppi, H., \& Saikkonen, P. (2008). Predicting U.S. recessions with dynamic binary response models. The Review of Economics and Statistics, 90(4), 777-791. doi:10.1162/rest.90.4.777.

Kuzmanovič, M., \& Sanfey, P. (2012). Can consumer confidence data predict real variables? Evidence from Croatia [Working Paper 151]. European Bank for Reconstruction and Deelopment.

Liu, W., \& Moench, E. (2014). What predicts US recessions? [Federal Reserve Bank of New York, Staff report No. 691].

Ludvigson, S. C. (2004). Consumer Confidence and Consumer Spending. Journal of Economic Perspectives, 18(2), 29-50. doi:10.1257/0895330041371222.

Merkle, D. M., Langer, G. E., \& Sussman, D. (2003). Consumer Confidence: Measurement and Meaning. Conference of the American Association for Public Opinion Research.
Nashville, Tennessee.

Mourougane, A., \& Moreno, R. (2002). Can confidence indicators be useful to predict short term real GDP growth? [Working paper No. 133]. European Central Bank.

OECD. (2016). Consumer confidence index (CCI) (indicator). doi: 10.1787/46434d78-en.

Schwarz, G. (1978). Estimating the Dimension of a Model. The Annals of Statistics, 6(2), 461-464, doi:10.1214/aos/1176344136.

Sergeant, K. A., Lugay, B., \& Dookie, M. (2011). Consumer confidence and economic growth: Case studies of Jamaica and Trinidad and Tobago. Economic Comission for Latin America and the Caribbean, UN.

Stock, J. H., \& Watson, M. W. (1993). A procedure for predicting recessions with leading indicators: Econometric issues and recent experience. In Business Cycles, Indicators and Forecasting. NBER Chapters (95-156). National Bureau of Economic Research, Inc.

Utaka, A. (2003). Confidence and the real economy - the Japanese case. Applied Economics, 35(3), 337-342. doi:10.1080/00036840210135205.

World Bank. (2016). Household final consumption expenditure, etc. (\% of GDP) [Data file]. Retrieved from http://data.worldbank.org/ indicator/NE.CON.PETC.ZS?page $=6$.

Wei, W. W. S. (1994). Time Series Analysis. Univariate and Multivariate Methods. Boston, MA: Addison-Wesley Publishing Co.

Mgr. Jiří Mazurek, Ph.D. Silesian University in Opava School of Business Administration in Karviná Department of Informatics and Mathematics mazurek@opf.slu.cz

Ing. Elena Mielcová, Ph.D.

Silesian University in Opava School of Business Administration in Karviná Department of Informatics and Mathematics mielcova@opf.slu.cz 


\section{Abstract}

\section{IS CONSUMER CONFIDENCE INDEX A SUITABLE PREDICTOR OF FUTURE ECONOMIC GROWTH? AN EVIDENCE FROM THE USA}

\section{Jiří Mazurek, Elena Mielcová}

The problem of the prediction of business cycles, and economic recessions in particular, belongs among the most important topics of contemporary macroeconomics. However, economists were not considerably successful when dealing with the recession forecasting so far, notably, the Great Recession of the late 2000s and early 2010s emerged rather surprisingly. The aim of this paper is to examine the statistical relationship (in terms of Granger causality) between the Consumer Confidence Index (CCI) and real GDP growth in the USA from 1960 to 2015 in order to find whether the $\mathrm{CCl}$ can be a suitable predictor of the economic growth, or economic recessions respectively. Also the short-term dynamics of four periods covering US economic recessions (1967-1978, 1975-1985, 1995-2005, and 2005-2015) was examined. The main results are that the CCl Granger causes GDP in the long-run, with the lag of 6 months. As for shorter periods, the CCI Granger caused GDP in three out of four examined periods, including the Great Recession (with the lag of 3 months), and only for the so called dot-com bubble period Granger causality was reversed, with GDP causing the $\mathrm{CCl}$ with the lag of 6 months. These results indicate that the $\mathrm{CCl}$ can be considered a suitable predictor of GDP at least for the USA, but more complex and broader study, including other major economics such as the European Union, Germany, or Japan, is certainly needed.

Key Words: Consumer Confidence Index, economic growth, GDP, Granger causality, VAR model.

JEL Classification: C22, C53, O47, 051.

DOI: 10.15240/tul/001/2017-2-003 